\title{
Türkiye'de Viyola Alanında Yazılmış Lisansüstü Tezler
}

\author{
DOI: 10.26466/opus.784467
}

$*$

\section{Serkan Özay *}

* Dr. Öğr. Üyesi, Niğde Ömer Halisdemir Üniversitesi, Eğitim Fakültesi, Niğde/Türkiye E-Posta: serkanozay@ohu.edu.tr

ORCID: $\underline{0000-0002-6485-9346}$

\section{Öz}

Bu araştırmanın amacı, Türkiye'de viyola ile ilgili yazılmış lisansüstü tezleri çeşitli değişkenlere göre analiz ederek daha sonra yapılacak çalışmalara katkıda bulunmaktır. Araştırmada YÖK Ulusal Tez Merkezi veri tabaninda bulunan ve tam metin erişime açlmasına izin verilen 81 adet lisansüstü tez doküman incelemesi tekniği ile analiz edilmiştir. Tezler; tür, üniversite, enstitü, konu ve yazlldıklar yıllara göre ele alınmıştır. Araştırmanın sonuçlarına göre; tezlerin, 56'sı yüksek lisans, 19'u sanatta yeterlik ve 6'sı da doktora tezidir. Tezlerin en fazla yazıldığ üniversitelerin Gazi Üniversitesi ve Mimar Sinan Güzel Sanatlar Üniversitesi olduğu, enstitü bazında en çok Sosyal Bilimler Enstitüsünde en az ise Fen Bilimleri Enstitüsünde yazıldığı, en fazla çalışmanın 2019 yılında yapıldığı, 2017-2020 yılları arası viyola ile ilgili yazılan lisansüstü tezlerin sayısının 21 adet olduğu görülmüştür. Doktora tezlerinin hepsinin "Eğitim" konusunda olduğu ve Sanatta Yeterlik tezlerinin en fazla oranla "Eser Inceleme" konusunda olduğu saptanmıştır. Viyola literatürüne kaynak ve bakış açısı sağlayacağı düşünüldüğ̈̈nden bu araştırmanın türünde çalışmaların tekrarlanması ve viyola ile ilgili yazılmış makalelerin incelenmesine yönelik çalışmaların da yapılması önerilmiştir.

Anahtar Kelimeler: viyola, lisansüstü tezler, viyola tezleri, doküman analizi 


\title{
Graduate Theses and Dissertations Written About The Viola in Turkey
}

\begin{abstract}
The aim of this research is to contribute to future studies by analyzing the graduate theses and dissertations written about the Viola in Turkey according to various variables. 81 graduate theses and dissertations in CoHE Thesis Center database, which are allowed for full text access, have been analyzed using the document review technique. Theses and dissertations are handled according to the type, university, institute, subject and year they were written. According to the results of the research, 56 of the theses and dissertations are Master's Degree theses, 19 are Proficiency in Art theses and 6 are Doctoral dissertations. It was observed that the highest number of theses and dissertations were made in Gazi University and Mimar Sinan Fine Arts University, on institute basis, the most were studied in Institute of Social Sciences and the least in Institute of Science, the most were studied in 2019 and the number of graduate theses (and dissertations) written about the Viola between 2017-2020 was 21. It was determined that all doctoral dissertations were on "Education" and Proficiency in Art theses were mostly on "Work Analysis". As it is thought that it will provide a source and perspective to the Viola literature, it is suggested that studies in this type of research should be repeated and studies of examining the articles written about the Viola should also be carried out.
\end{abstract}

Keywords: viola, graduate theses-dissertations, viola theses-dissertations, document review 


\section{Giriş}

Yaylı çalgılar denilince çoğunlukla akla keman gelmektedir ve bu çalgılar "keman ailesi" olarak da adlandırılmaktadır. Bunun nedeni ise kemanın, yaygın kullanımı ve eser sayısının fazla olmasının yanısıra çoğu müzik tür ve biçimine uygun bir ses yapısına sahip olmasıdır. Keman aynı zamanda yaylı çalg1 ve çalgı eğitimi hakkındaki bilimsel araştırmaların da merkezindedir. Keman ailesinden olan viyola ile ilgili ise özellikle yapısal anlamda geçirdiği değişimi incelemek için yeterli içeriğe sahip kaynak bulmak zordur.

Viyola 17. yüzyıldan bu yana benzerliğinden dolayı kemana göre konumlandırılmıştır. Şekerkaran'a (1997) göre "viyola, görünüşü ve çalınışı yönünden keman gibi bir çalgıdır. Yalnız kemandan biraz daha büyük ve daha kalın sesler çıkarabilen bir alettir. Ayrıca seslerinin niteliği ve rengiyle kemandan farklıdır". György Ligeti'nin (2001) "Solo Viyola İçin Sonat" başlıklı eserinde kaleme aldığı önsözdeki "Viyola görünüşte sadece büyük bir kemandır, ama bir beşli pes akort edilir. Gerçekte ise bu iki enstrüman arasında dünyalar vardır" sözü viyolanın insanlar arasında kemandan ayrı bir çalgı olarak görülmediği yönünde fikir verir. Bütün viyolacıların yakındığı bu durum, viyolanın gelişim sürecini inceleyen çalışmalarda da etkisini sürdürmüştür.

Yaylı çalgılar sanatı ve eğitiminde keman ve viyola benzer disiplinler olarak ele alınıp performans, teknik, yöntem ve metot olarak aynı aşamalar takip edilerek çalışmalar sürdürülmüştür. Hatta bilimsel olarak da onaylanan bu görüşte, bazı araştırmacıların (Kumtepe, 2019; Okay ve Kurtaslan, 2013; Baykal, 2012; Öztürk ve Özay, 2008; Başdan, 2008; Varış, 2002; Bilginer, 2001) keman ve viyolayı beraberce konu alan çalışmaları olduğu bilinmektedir. Sadece Türkçe'de değil batı dillerinde de zengin kaynakçaya sahip olmayan viyola, 1600'lü yıllardan itibaren yapısal değişiklikler göstermiştir ve hiçbir zaman tek bir forma sahip ve yaygın kullanılan bir enstüruman olamamıştır. Tel sayısı ve akort olarak sayısız değişime uğramıştır (Yılmaz, 2017, s.31).

Viyol adı verilen ilkel ve yaylı çalgılardan geldiği düşünülmekte olan bu çalgı, viyol ailesinin rönesans ve barok döneminde genişlemeye başlamasıyla, viole da braccio (kol viyolü) ve viole de gamba (bacak viyolü) olarak iki gruba ayrılmıştır. Viyol, yay ile çalınan perdeli ve telli çalgılar için kullanılan genel bir terimdir (Akyürek; 2004, s.21). Viyoller çalgı yapımcıları tarafından farklı formlara dönüştürülüp küçük değişiklikler yapılarak son halini 19. 
yüzyılda almıştır (Özkarar, 2017, s.17). Yılmaz'a (2017) göre; söz konusu gelişimi ayrıntılı bir şekilde incelediğimizde bugünkü yaylı çalgıların merkez çalgısı keman değil viyolanın olduğu rahatlıkla söylenebilir. Bu söylem üzerine viyola alanında araştırmacıların yeni bilimsel araştırmalar yaparak literatüre yeni kazanımlar sağlaması gerektiği düşünülmektedir.

Bilimsel araştırma, analiz ve yorumlamayla birlikte pozitivist bir bakış açısı gerektirir. Fikir aşamasında bilimsel düşünce, eylem aşamasında bilimsel araştırma esaslarının birleşiminden oluşur. "Bilimsel araştırma yöntemlerinin amacı, ispatlanmış veriye ulaşmak için sistematik çalışmalara ve analizlere dayalı genelleştirilebilir doğru bilgilere ulaşmaktır" (Puy, 2020). Bilimsel araştırmalar ülkemizde çoğunlukla üniversiteler bünyesinde gerçekleştirilir ve üniversitelerin en önemli işlevlerinden biri lisansüstü eğitim sürecinde yapılan bilimsel tez çalışmalarıdır. Lisansüstü tez çalışmaları müzik alanında üç farklı türde yapılmaktadır. Bunlar doktora tezleri, yüksek lisans tezleri ve doktoraya eşdeğer- sanatta yeterlik tezleridir. Müzik eğitimine yönelik olan tezler genel olarak müzik eğitim anabilim dallarının lisansüstü programlarında devam etmektedir. Tezli yüksek lisans ve doktora programları, bu bölümlerin bağlı oldukları eğitim bilimleri enstitüleri güzel sanatlar eğitimi anabilim dallarında ve bazı üniversitelerde ise sosyal bilimler enstitüleri müzik eğitimi bilim dalları programlarında yer almaktadır. Sanatta yeterlik programları, tarihsel ve yapısal incelemeye yönelik (organoloji), performansa yönelik, ekollere yönelik, eser ve etüt incelemeye yönelik amaçlar güderek konservatuvarların ve güzel sanatlar fakültelerinin lisans düzeylerinin devamı niteliğinde olan sosyal bilimler enstitüsü veya güzel sanatlar entitülerine bağlı müzik ana sanat dallarında yapılmaktadır.

Türkiye'de üniversitelerin sayılarının artması, lisans öğrencilerinin artmasına, buna paralel olarak verilen mezun sayılarının artmasına ve mezun öğrencilerin eğitimlerine devam niteliğinde bilgi ve kabiliyetlerini geliştirme adına lisansüstü programlarına katılmalarına ve tez çalışmalarının artmasına neden olmuştur. Günümüzde yazılan lisansüstü tezlere çalışmanın yapıldığ 1 üniversite kütüphanelerinden ve Yükseköğretim Kurulu Başkanlığı Ulusal Tez Merkezi'nden (https://tez.yok.gov.tr/UlusalTezMerkezi/) ulaşılabilmektedir.

Ülkemizde yapılan ve yapılacak olan tez çalışmalarına kaynak oluşturması ve ilgili alanda çalışılan konularda bilimsel çalışmalarda gelinen seviyenin sonraki araştırmalara kaynak olması amacıyla yazılmış lisansüstü tezleri 
inceleyen, belirli bir alanda belirli bir dönemde ve belirli bir bölgede kişiler ya da kurumlar tarafından üretilmiş yayınların ve bu yayınlar arasındaki ilişkilerin sayısal olarak analizini ortaya koyan bibliyometrik ve bibliyografik (kaynakçasal) bir çok araştırma vardır.

Farklı konularda yapılan lisansüstü tez incelemelerinden; kontrbas üzerine yazılmış lisansüstü tezlerin incelenmesi (Birel ve Qader, 2017), yaylı çalgılar üzerine yazılmış lisansüstü tez bibliyografyası (Demirbatır, 2001), oda müziği konusunda yapılmış lisansüstü tez çalışmaları (Orhan ve Tunca, 2014), piyano üzerine yapılmış lisansüstü tez çalışmaları (Toptaş, 2013), viyolonsel alanında yapılmış lisansüstü tez çalışmalarının incelenmesi (Orhan, 2012), vokal müzikte piyano eşlik alanında yapılmış lisansüstü tez çalışmaları (Kaptanoğlu ve Çanakçı, 2015), gitar alanında yapılmış lisansüstü tez çalışmalarının incelenmesi (Alyörük, 2016), kabak kemane üzerine yapılmış tez çalışmalarının incelenmesi (Özay, 2017), müzik teknolojileri alanında yapılan tez çalışmalarının incelenmesi (Delikara, 2019) v.b. gibi makale ve bildiriler literatürde yer almaktadır. Viyola alanı üzerine yapılmış lisansüstü tez çalışmaları ile ilgili makaleler ise Varış, 2012; Tebiş ve Okay, 2013; Çeşit, 2015 ve Sonsel, 2018 tarafından yazılmıştır. Bu araştırma konu içeriği bakımından yapılan önceki araştırmalar ile doğrudan ilişkilidir ve önceki çalışmaların devamı niteliğindedir.

Dolayısıyla araştırmanın amacı, Türkiye'de viyola ile ilgili yazılmış lisansüstü tezleri tespit edip farklı değişkenlere göre dağılım analizini yaparak daha sonra yapılacak olan çalışmalara katkıda bulunmaktır. Bu amaç doğrultusunda cevaplanacak sorular şu şekilde belirlenmiştir:

- Türkiye'de viyola ile ilgili yazılmış lisansüstü tezlerin türlerine göre dağllımları nasıldır?

- Türkiye'de viyola ile ilgili yazılmış lisansüstü tezlerin üniversitelere göre dağılımları nasıldır?

- Türkiye'de viyola ile ilgili yazılmış lisansüstü tezlerin enstitülere göre dağılımları nasıldır?

- Türkiye'de viyola ile ilgili yazılmış lisansüstü tezlerin yazıldığı yıllara göre dağılımları nasıldır?

- Türkiye'de viyola ile ilgili yazılmış lisansüstü tezlerin konularına göre dağılımları nasıldır? 


\section{Yöntem}

Araştırmada nitel araştırma yöntemlerinden biri olan doküman incelemesi tekniği kullanılmıştır. "Doküman incelemesi, araştırılması hedeflenen olgu veya olgular hakkında bilgi içeren yazılı materyallerin analizini kapsar (Yıldırım ve Şimşek, 2018, s.189). Araştırmanın dokümanları, YÖK Ulusal Tez Merkezi'nin tez tarama sayfasından, "viyola" anahtar sözcügü ile aranacak alan "tümü", izin durumu "tümü", tez türü "tümü" olarak taratılmıştrr. Yapılan arama sonucunda 125 adet lisansüstü tez listelenmiş, gelişmiş arama seçeneğinde ise "aranılacak kelime(ler)" viyola ve müzik, "aranacak alan" tümü seçilmiş ve 111 adet lisansüstü tez listelenmiştir. Yapılan detaylı inceleme sonucu viyola ile doğrudan ilgili, ilk araştırmanın yapıldığı 1990 yılından 2020 yılına kadar, olan tezler içerik olarak incelenmiş ve izinli/izinsiz olarak toplam 93 adet tez tespit edilmiş, aranacak alan "tez adı" olarak yapılan arama sonucu ile de taramanın sağlaması yapılmıştır. Adında "viyola" terimi bulunan ancak konu alanı "biyoloji" olan bir yüksek lisans tezi kapsam dışı bırakılmış, araştırmanın alanı ile ilgili tez sayısı 92 olarak belirlenmiştir. Araştırma 2020 yılının ilk 8 ayına kadar YÖK Ulusal Tez Merkezi veri tabanından ulaşılabilen izinli çalışmaları kapsamaktadır. Bu çalışmaların izin durumları Tablo 1. de gösterilmiştir. Araştırmanın örneklemini oluşturan ve amaçsal örnekleme yoluyla belirlenen izinli durumda, ve tam metin halinde ulaşılabilen toplamda 81 adet tez analiz edilmiştir.

Tablo 1. YÖK Ulusal Tez Merkezinde Bulunan Viyola ile İlgili Tezlerin İzin Durumlarna Göre Dağılımlan

\begin{tabular}{lllllllll}
\hline \multirow{2}{*}{ İzin Durumu } & \multicolumn{2}{c}{ Yüksek Lisans } & \multicolumn{2}{c}{ Sanatta Yeterlik } & \multicolumn{2}{c}{ Doktora } & \multicolumn{2}{c}{ Toplam } \\
\cline { 2 - 9 } & $\mathbf{f}$ & $\mathbf{\%}$ & $\mathbf{f}$ & $\mathbf{\%}$ & $\mathbf{f}$ & $\mathbf{\%}$ & $\mathbf{f}$ & $\mathbf{\%}$ \\
\hline İzinli & 56 & 83,6 & 19 & 100 & 6 & 100 & 81 & 88,04 \\
\hline İzinsiz & 11 & 16,4 & & & & & 11 & 11,96 \\
\hline Toplam & $\mathbf{6 7}$ & $\mathbf{1 0 0}$ & $\mathbf{1 9}$ & $\mathbf{1 0 0}$ & $\mathbf{6}$ & $\mathbf{1 0 0}$ & $\mathbf{9 2}$ & $\mathbf{1 0 0}$ \\
\hline
\end{tabular}

Tablo 1 incelendiğinde YÖK Ulusal Tez Merkezi veri tabanında bulunan viyola ile ilgili yazılmış yüksek lisans tezlerinin \% 11,96'lık kısmını oluşturan 11 tezin erişime izinli olmadığı, sanatta yeterlik ve doktora tezlerinin ise tamamının erişime izinli olduğu görülmektedir. 


\section{Bulgular ve Yorumlar}

Araştırma alt amaçları doğrultusunda incelenen tezlerden elde edilen veriler tablolaştırılmış ve tablolar yorumlanmıştır.

Tablo 2. Viyola ile İlgili Yazılmış Lisansüstü Tezlerin Türlerine Göre Dağılımlan

\begin{tabular}{lcl}
\hline Tez Türü & f & \% \\
\hline Yüksek Lisans & 56 & 69,14 \\
\hline Sanatta Yeterlik & 19 & 23,45 \\
\hline Doktora & 6 & 7,41 \\
\hline Toplam & $\mathbf{8 1}$ & $\mathbf{1 0 0}$ \\
\hline
\end{tabular}

Tablo 2 incelendiğinde, viyola ile ilgili yazılan lisansüstü tezlerin türlerine göre $\% 7,41^{\prime}$ i doktora tezi, $\% 69,14$ 'ü yüksek lisans tezi, $\% 23,45^{\prime} \mathrm{i}$ ise sanatta yeterlik tezi olduğu tespit edilmiştir. Bu tablodan kaynaklı oluşan çıkarımlar ise; lisansüstü tezlerin yarısından fazlasının yüksek lisans tezleri olduğu ve en az araştırma türünün de doktora tezleri olduğu yönündedir.

Daha önce yapılan çalışmalarda, Varış, 2012'de; incelenen izinli toplam 38 lisansüstü tezin 28 yüksek lisans, 1 doktora, 9 sanatta yeterlik tezi olduğu, Tebiş ve Okay, 2013'de; izinli/izinsiz toplamda 53 adet viyola ile ilgili lisansüstü tez olduğu, Çeşit, 2015'de; izinli toplam 49 lisansüstü tezin 37 yüksek lisans, 1 doktora, 11 sanatta yeterlik tezi olduğu ve Sonsel, 2018'de; izinli toplam 57 lisansüstü tezin 41 yüksek lisans, 2 doktora, 14 sanatta yeterlik tezi olduğu görülmektedir. Bu verilere göre viyola alanında yapılan yeni lisansüstü tez çalışmalarının olduğu ve literatüre 23 lisansüstü tezin kazandırıldığı ve özellikle doktora düzeyinde yazılan tez sayısının iki yıl içerisinde önemli oranda arttı̆̆ söylenebilir.

Tablo 3. Viyola ile İlgili Yazılmış Lisansüstü Tezlerin Üniversitelere Göre Dağıllımları

\begin{tabular}{lllllllll}
\hline \multirow{2}{*}{ Üniversite Adları } & \multicolumn{2}{l}{$\begin{array}{l}\text { Yüksek } \\
\text { Lisans }\end{array}$} & \multicolumn{2}{c}{$\begin{array}{l}\text { Sanatta } \\
\text { Yeterlik }\end{array}$} & \multirow{2}{*}{ Doktora } & \multicolumn{2}{c}{ Toplam } \\
\cline { 2 - 10 } & f & \% & f & \% & f & \% & f & \% \\
\hline Afyon Kocatepe Üniversitesi & 4 & 7,14 & & & & 4 & 4,94 \\
\hline Anadolu Üniversitesi & 2 & 3,57 & 2 & 10,52 & & 4 & 4,94 \\
\hline Ankara Üniversitesi & 1 & 1,78 & & & & 1 & 1,23 \\
\hline Atatürk Üniversitesi & 2 & 3,57 & & & 2 & 2,47 \\
\hline Başkent Üniversitesi & 1 & 1,78 & & & & 1 & 1,23 \\
\hline Bolu Abant İzzet Baysal Üniversitesi & 2 & 3,57 & & & 2 & 2,47 \\
\hline Burdur Mehmet Akif Ersoy Üniversitesi & 1 & 1,78 & & & & 1 & 1,23 \\
\hline Bursa Uludağ Üniversitesi & 3 & 5,35 & 2 & 10,52 & & 5 & 6,17 \\
\hline
\end{tabular}




\begin{tabular}{|c|c|c|c|c|c|c|c|c|}
\hline Çukurova Üniversitesi & 1 & 1,78 & & & & & 1 & 1,23 \\
\hline Dokuz Eylül Üniversitesi & 3 & 5,35 & 2 & 10,52 & & & 5 & 6,17 \\
\hline Erciyes Üniversitesi & 1 & 1,78 & & & & & 1 & 1,23 \\
\hline Gazi Üniversitesi & 7 & 12,5 & & & 5 & 83,33 & 12 & 14,81 \\
\hline Hacettepe Üniversitesi & 1 & 1,78 & 1 & 5,26 & & & 2 & 2,47 \\
\hline Haliç Üniversitesi & & & 1 & 5,26 & & & 1 & 1,23 \\
\hline İnönü Üniversitesi & 1 & 1,78 & & & 1 & 16,67 & 2 & 2,47 \\
\hline İstanbul Üniversitesi & 5 & 8,93 & 4 & 21,05 & & & 9 & 11,11 \\
\hline Marmara Üniversitesi & 2 & 3,57 & & & & & 2 & 2,47 \\
\hline Mersin Üniversitesi & 1 & 1,78 & & & & & 1 & 1,23 \\
\hline Mimar Sinan Güzel Sanatlar Üniversitesi & 7 & 12,5 & 5 & 26,31 & & & 12 & 14,81 \\
\hline Necmettin Erbakan Üniversitesi & 1 & 1,78 & & & & & 1 & 1,23 \\
\hline Niğde Ömer Halisdemir Üniversitesi & 2 & 3,57 & & & & & 2 & 2,47 \\
\hline Pamukkale Üniversitesi & 1 & 1,78 & & & & & 1 & 1,23 \\
\hline Trakya Üniversitesi & 6 & 10,71 & 2 & 10,52 & & & 8 & 9,88 \\
\hline Van 100.Y1l Üniversitesi & 1 & 1,78 & & & & & 1 & 1,23 \\
\hline Toplam & 56 & 100 & 19 & 100 & 6 & 100 & 81 & 100 \\
\hline
\end{tabular}

Tablo 3 incelendiğinde viyola ile ilgili olan lisansüstü tezlerin $\% 14,81$ oranla çoğunluğunun Gazi Üniversitesi ve Mimar Sinan Güzel Sanatlar Üniversitesi'nde yazıldığı görülmektedir. Doktora tezlerinin çoğunluğunun \%83,33 oranla Gazi Üniversitesi bünyesinde yapılan araştırmalar olduğu görülmektedir. Sanatta Yeterlik tezlerinin \%26,35'lik oranla çoğunluğunun yazıldığı üniversiteler ise Mimar Sinan Güzel Sanatlar Üniversitesi ve \%21,05'lik oranla İstanbul Üniversitesidir. Toplam lisanüstü tezlerin çoğunluğunu oluşturan yüksek lisans tezleri içerisinde \%12,5'lik oranlarıyla Gazi Üniversitesi'nin ve Mimar Sinan Güzel Sanatlar Üniversitesi'nin çalışmaları bulunmaktadır. En az sayıda lisansüstü çalışmaların ise birer adet yüksek lisans teziyle; Ankara Üniversitesi, Başkent Üniversitesi, Burdur Mehmet Akif Ersoy Üniversitesi, Çukurova Üniversitesi, Erciyes Üniversitesi, Mersin Üniversitesi, Necmettin Erbakan Üniversitesi, Pamukkale Üniversitesi, Van 100.Yıl Üniversitesi olduğu, Haliç Üniversitesinde de bir adet sanatta yeterlik tez çalışması bulunduğu tespit edilmiştir.

Daha önceki (Sonsel, 2018; Çeşit, 2015; Tebiş ve Okay, 2013; Varış, 2012) çalışmalarda üniversiteler bünyesinde yazılan lisansüstü tezlerde en fazla çalışmayı Mimar Sinan Güzel Sanatlar Üniversitesi'nin yaptığı sonucu çıkarılmıştır. Bu çalışmada ise Mimar Sinan Güzel Sanatlar Üniversitesi ile birlikte Gazi Üniversitesi'nin de en fazla lisansüstü tez çalışması yaptığı, oranlarının aynı olduğu saptanmıştır. Ayrıca en son yapılan bibliyografik çalışma (Sonsel,2018) üzerinden geçen süre içerisinde, bazı üniversitelerin viyola ile ilgili 
lisansüstü çalışmalarını arttırmış olduğu, Başkent Üniversitesi, Ankara Üniversitesi, Mersin Üniversitesi, Burdur Mehmet Akif Ersoy Üniversi'nde de viyola ile ilgili lisansüstü tez çalışması yapıldığı ve İnönü Üniversitesi bünyesinde de doktora çalışmalarının başladığı söylenebilir.

Tablo 4. Viyola ile İlgili Yazılmış Lisansüstü Tezlerin Enstitülere Göre Dağılımları

\begin{tabular}{lllllllll}
\hline \multirow{2}{*}{ Enstitü Adı } & \multicolumn{2}{l}{$\begin{array}{l}\text { Yüksek } \\
\text { Lisans }\end{array}$} & \multicolumn{2}{l}{$\begin{array}{l}\text { Sanatta } \\
\text { Yeterlik }\end{array}$} & \multicolumn{2}{c}{ Doktora } & \multicolumn{2}{c}{ Toplam } \\
\cline { 2 - 11 } & $\mathbf{f}$ & $\mathbf{\%}$ & $\mathbf{f}$ & $\mathbf{\%}$ & $\mathbf{f}$ & $\mathbf{\%}$ & $\mathbf{f}$ & $\mathbf{\%}$ \\
\hline Sosyal Bilimler Enstitüsü & 35 & 62,50 & 16 & 84,21 & 1 & 16,66 & 52 & 64,20 \\
\hline Eğitim Bilimleri Enstitüsü & 12 & 21,43 & & & 3 & 50,00 & 15 & 18,52 \\
\hline Fen Bilimleri Enstitüsü & 3 & 5,36 & & & 2 & 33,34 & 5 & 6,17 \\
\hline Güzel Sanatlar Enstitüsü & 6 & 10,71 & 3 & 15,79 & & & 9 & 11,11 \\
\hline Toplam & $\mathbf{5 6}$ & $\mathbf{1 0 0}$ & $\mathbf{1 9}$ & $\mathbf{1 0 0}$ & $\mathbf{6}$ & $\mathbf{1 0 0}$ & $\mathbf{8 1}$ & $\mathbf{1 0 0}$ \\
\hline
\end{tabular}

Tablo 4 incelendiğinde viyola ile ilgili yazılan lisansüstü tez çalışmalarının toplamda \%64,20'sinin Sosyal Bilimler Enstitüsünde yapıldığ görülmektedir. En az çalışma \%6,17 ile Fen Bilimleri Enstitüsündedir. Tabloda doktora tezlerinin yarısının Eğitim Bilimleri Enstitüsünde yazıldığı ve Güzel Sanatlar Enstitüsünde konuyla ilgili yazılan bir doktora tezinin bulunmadığı saptanmıştır. Sanatta yeterlik tezi oranlarının ise \%84,21 ile en çok Sosyal Bilimler Enstitüsünde olduğu, Eğitim Bilimleri Enstitüsü ve Fen Bilimleri Enstitüsünde konuyla ilgili tez çalışması olmadığı görülmüştür. Yüksek lisans tezlerinin yarısından fazlasının Sosyal Bilimler Enstitüsü bünyesinde yazılmış olduğu, \%5,36 oranıyla konuyla ilgili en az çalışmanın ise Fen Bilimleri Enstitüsünde olduğu saptanmıştır.

Fen Bilimleri Enstitülerindeki çalışmaların 4'ü Gazi Üniversitesi, 1'i ise İnönü Üniversitesi bünyesinde yapılmıştır. Gazi Üniversitesi'nde müzik ile ilgili lisansüstü çalışmalarının günümüzde eğitim bilimleri enstitüsünde ve İnönü Üniversitesi'nde ise eğitim bilimleri ve sosyal bilimler enstitülerinde yapıldığı bilinmektedir. İçerik olarak Fen Bilimleri Enstitülerinde müzik ile ilgili çalışmalar diğer enstitülere kaydırıldığı söylenebilir. Çeşit' in (2015) çalışmasında, Sosyal Bilimler Enstitüsünün 37, Eğitim Bilimleri Enstitüsünün ise 8 lisansüstü tez çalışması yaptığı saptanmıştır. Bu çalışmada Sosyal Bilimler Enstitüsü, geçen zaman içerisinde 14 lisansüstü tez ile literatüre katkı sağlarken, Eğitim Bilimleri Enstitülerinde bu katkının 7 tez olduğu tespit edilmiştir. 
Tablo 5. Viyola ile İlgili Yazılmış Lisansüstü Tezlerin Yazıldı̆̆ı Yıllara Göre Dağılımları

\begin{tabular}{|c|c|c|c|c|c|c|c|c|}
\hline \multirow{2}{*}{ Yillar } & \multicolumn{2}{|c|}{ Yüksek Lisans } & \multicolumn{2}{|c|}{ Sanatta Yeterlik } & \multicolumn{2}{|c|}{ Doktora } & \multicolumn{2}{|c|}{ Toplam } \\
\hline & $\mathbf{f}$ & $\%$ & $\mathrm{f}$ & $\%$ & $f$ & $\%$ & $\mathrm{f}$ & $\%$ \\
\hline 1994 & 1 & 1,78 & & & & & 1 & 1,23 \\
\hline 1995 & 1 & 1,78 & & & & & 1 & 1,23 \\
\hline 1996 & 1 & 1,78 & & & & & 1 & 1,23 \\
\hline 1997 & 1 & 1,78 & & & & & 1 & 1,23 \\
\hline 1998 & 1 & 1,78 & & & & & 1 & 1,23 \\
\hline 1999 & 1 & 1,78 & & & & & 1 & 1,23 \\
\hline 2001 & & & 1 & 5,263 & 1 & 16,66 & 2 & 2,46 \\
\hline 2002 & 2 & 3,57 & 1 & 5,263 & 1 & 16,66 & 4 & 4,94 \\
\hline 2004 & 3 & 5,36 & & & & & 3 & 3,70 \\
\hline 2005 & 1 & 1,78 & 1 & 5,263 & & & 2 & 2,46 \\
\hline 2006 & 4 & 7,14 & & & & & 4 & 4,94 \\
\hline 2007 & 3 & 5,36 & 2 & 10,526 & & & 5 & 6,17 \\
\hline 2008 & 5 & 8,93 & & & & & 5 & 6,17 \\
\hline 2009 & 5 & 8,93 & 1 & 5,263 & & & 6 & 7,40 \\
\hline 2010 & 4 & 7,14 & 2 & 10,526 & & & 6 & 7,40 \\
\hline 2011 & 1 & 1,78 & & & & & 1 & 1,23 \\
\hline 2012 & 4 & 7,14 & 3 & 15,792 & & & 7 & 8,64 \\
\hline 2013 & 2 & 3,57 & & & & & 2 & 2,46 \\
\hline 2014 & 2 & 3,57 & 1 & 5,263 & & & 3 & 3,70 \\
\hline 2015 & 2 & 3,57 & & & & & 2 & 2,46 \\
\hline 2016 & 1 & 1,78 & 1 & 5,263 & & & 2 & 2,46 \\
\hline 2017 & 1 & 1,78 & 2 & 10,526 & & & 3 & 3,70 \\
\hline 2018 & 2 & 3,57 & 2 & 10,526 & 2 & 33,34 & 6 & 7,40 \\
\hline 2019 & 6 & 10,71 & 2 & 10,526 & 2 & 33,34 & 10 & 12,34 \\
\hline 2020 & 2 & 1,78 & & & & & 2 & 2,46 \\
\hline Toplam & 56 & 100 & 19 & 100 & 6 & 100 & 81 & 100 \\
\hline
\end{tabular}

Tablo 5 incelendiğinde viyola ile ilgili en fazla lisansüstü tez çalışmasının \%12.34 oranla 2019 yılında yapıldığı tespit edilmiştir. Doktora tezlerinin \%33,34 oranlarla en çok 2018 ve 2019 yıllarında yazıldı̆̆ı, sanatta yeterlik tezlerinin 15,792 oranla en çok 2012 yılında yazıldı̆̆ı ve en fazla yüksek lisans tezinin ise \%10,71 oranla 2019 yılında yazılmış olduğu görülmektedir. 2000 ve 2003 yıllarında araştırmanın konusuyla ilgili yapılan taramada lisansüstü tez çalışmalarının var olduğu tespit edilmiş fakat tam metinlerine ulaşılamadığg için kapsam dişında bırakılmıştır.

Tabloya göre 2017-2020 yılları arası viyola ile ilgili yazılan lisansüstü tezlerin sayısının, şimdiye kadar yazılan tezlere oranla \%25,92, yani 21 adet gibi bir değere sahip olması son dört yılda viyola ile ilgili lisansüstü tez çalışmalarının arttı̆̆ı söylenebilir. Bu durum yapılan çalışmanın önemini de vurgulamaktadir. 
Tablo 6. Viyola ile İlgili Yazılmış Lisansüstü Tezlerin Konularına Göre Dağılımları

\begin{tabular}{|c|c|c|c|c|c|c|c|c|}
\hline \multirow{2}{*}{ Tez Konuları } & \multicolumn{2}{|c|}{ Yüksek Lisans } & \multicolumn{2}{|c|}{ Sanatta Yeterlik } & \multicolumn{2}{|c|}{ Doktora } & \multicolumn{2}{|c|}{ Toplam } \\
\hline & f & $\%$ & $\mathrm{f}$ & $\%$ & $f$ & $\%$ & f & $\%$ \\
\hline Eğitim & 17 & 30,36 & & & 6 & 100 & 23 & 28,39 \\
\hline Eser İnceleme & 11 & 19,64 & 9 & 47,368 & & & 20 & 24,69 \\
\hline Etüt İnceleme & 2 & 3,57 & 1 & 5,263 & & & 3 & 3,70 \\
\hline Metot İnceleme & 6 & 10,71 & & & & & 6 & 7,40 \\
\hline Tarihsel İnceleme & 2 & 3,57 & 1 & 5,263 & & & 3 & 3,70 \\
\hline Yapısal İnceleme & 2 & 3,57 & 1 & 5,263 & & & 3 & 3,70 \\
\hline Çalışma Önerisi & 7 & 12,50 & 2 & 10,527 & & & 9 & 11,11 \\
\hline Literatür & 4 & 7,14 & 1 & 5,263 & & & 5 & 6,17 \\
\hline Biyografi & 1 & 1,78 & 1 & 5,263 & & & 2 & 2,47 \\
\hline Biyografi/Eser İnceleme & 3 & 5,36 & 1 & 5,263 & & & 4 & 4,94 \\
\hline Ekoller & & & 2 & 10,527 & & & 2 & 2,47 \\
\hline Müzisyen Sağlığ1 & 1 & 1,78 & & & & & 1 & 1,23 \\
\hline Toplam & 56 & 100 & 19 & 100 & 6 & 100 & 81 & 100 \\
\hline
\end{tabular}

Tablo 6 incelendiğinde yapılan en fazla lisansüstü çalışmanın 23 tez ve 28.39'luk oranla "Eğitim" konulu olduğu, ikinci sırada ise 20 tez ve \%24,69'luk oranla "Eser İnceleme" konulu olduğu görülmektedir. Tabloda yüksek lisans çalışmalarının 17 tez ve \%30,36'lık oranla en fazla "eğitim" konusunu, ikinci sirada ise 11 tez ve \%19,64'lük oranla "eser inceleme" konusunu işlediği görülmektedir. Doktora tezlerinin 6 tez ve \%100'lük oranla "eğitim" konusunda olduğu başka konularda doktora tezinin olmadiğı saptanmiştır. Sanatta Yeterlik tezlerinin ise "Eser İnceleme"nin 9 tez ve \%47,37'lik oranla en fazla konulu olduğu görülmüştür.

Daha önceki (Sonsel, 2018; Çeşit, 2015; Tebiş ve Okay, 2013; Varış, 2012) çalışmalarda, tablodaki konu başlıklarının aynı olmasına rağmen sayısal ifadelerinin farklılık gösterdiği görülebilir. Değer farklarının, yazarların konu içeriklerine aldıkları ifadelerin çeşitliliğinden kaynaklı olduğu, bu nedenden dolayı farkların görüldüğü düşünülmektedir.

\section{Sonuç ve Tartışma}

Araştırmadan elde edilen sonuçlara göre;

- YÖK Ulusal Tez Merkezi'nin tez tarama sayfasindan elde edilen verilere göre; Türkiye'de viyola ile ilgili 1990-2020 yılları arasında yazılan 92 lisansüstü tez saptanmıştır ancak araştırmanın konusuyla ilgili izin durumu kaynaklı ulaşılamayan 11 çalışma bulunmaktadır. Tüm alanlarda 
yazılan tezlerdeki izin durumunun tekrar gözden geçirilerek araştırmacıların ulaşımına açılması kaynakça ve içeriklerin çeşitlenmesi açısından katkı sağlayacaktır.

- Viyola ile ilgili yazılan lisansüstü tezlerin incelenmesiyle ilgili son yapılan makalenin verileriyle (57 tez: Sonsel, 2018) karşılaştırıldığında viyola alanında yazılan yeni lisansüstü tezlerin olduğu ve literatüre 24 tane daha lisansüstü tezin kazandırıldığı saptanmış ve doktora düzeyinde yazılan tez sayısının iki yıl içerisinde üç kat arttığı gözlemlenmiştir. Viyola konulu yapılan çalışmaların çoğunlukla yüksek lisans tezi olduğu, çalışmaların son dört yıl içerisinde farkedilir derecede artmasına rağmen doktora düzeyinde tez çalışmalarının sayısının arttırılması önerilebilir.

- Viyola ile ilgili lisansüstü tez çalışmalarının en fazla yapıldığı üniversiteler; Gazi Üniversitesi ve Mimar Sinan Güzel Sanatlar Üniversitesi olduğu görülmüş̧ür. Doktora tezlerinin \%83,33'lük kısmının Gazi Üniversitesi bünyesinde yazıldığı tespit edilmiş ve en fazla sanatta yeterlik tezinin ise Mimar Sinan Güzel Sanatlar Üniversitesinde yazıldığı görülmüş̧ür. Ayrıca en son yapılan çalışma üzerinden geçen süre içerisinde, bazı üniversiteler viyola ile ilgili lisansüstü tez çalışmalarını arttırırken dört üniversitenin bünyesinde daha bu konuyla ilgili lisansüstü tez çalışmasının yapıldığı saptanmıştır. Artan doktora tez çalışmaları da üniversitelerde istihdam edilecek dr. dereceli viyola eğitimcisi akademisyenler ile literatüre kazandırılacak yeni çalışmaların da hızlı ve nitelikli bir şekilde artacağı şeklinde yorumlanabilir.

- Viyola ile ilgili lisansüstü tez çalışmalarının enstitü bazında en çok $\% 64,20$ 'lik oranla 52 tanesinin Sosyal Bilimler Enstitüsü, en az ise \%6,17'lik oranla 5 tanesinin Fen Bilimleri Enstitüsü bünyesinde yapıldığı tespit edilmiştir. Viyola ile ilgili yapılan lisansüstü çalışmalarda konu içeriği olarak "Eğitim" in fazla olması fakat Eğitim Bilimleri Enstitülerinde sadece 15 lisansüstü çalışmanın olmasından dolayı yeni yapılacak çalı̧̧malarda viyola eğitimi konusuna daha fazla yer verilmesi önerilebilir.

- Viyola ile ilgili en fazla lisansüstü tez çalışmasının \%12,34'lük oranla 2019 yılında yapıldığı, doktora tezlerinin \%33,34 oranıyla 2018 ve 2019 yıllarında yazıldığı, en fazla yüksek lisans tezinin ise \%10,71'le 2019 yılında yazıldığı saptanmıştır. 2017-2020 yılları arası viyola ile ilgili yazılan lisanüstü tezlerin sayısının \%25,92'lik bir oranla 21 adet olduğu yani son dört 
yılda viyola ile ilgili lisansüstü tez çalışmalarının yoğunlukta olduğu görülmüş̧ür. Bu durum, yapılan çalışmanın gerekliliğini ve önemini vurgulamaktadır. Benzer bibliyografya çalışmalarının çeşitlendirilerek ve detaylandırılarak tekrar edilmesi önerilebilir.

- Viyola ile ilgili yapılmış lisansüstü tez çalısmalarının \%28,39'luk oranla 23 tezin "Eğitim" konusunda, ikinci sırada ise \%23,46"lik oranla 20 tezin "Eser İnceleme" konusunda olduğu görülmüştür. Doktora tezlerinin hepsinin "Eğitim" konusunda olduğu saptanmış ve Sanatta Yeterlik tez çalışmalarının 9 tez ve \%47,37'lik oran ile "Eser İnceleme" konusunda olduğu görülmüştür. Tez çalışmalarında saptanan sonuçlar dikkate al1nırsa, oluşturulacak viyola sınav ve konser repertuvarlarına ve viyola eğitim programlarına yön verebileceği düşünülmektedir.

- Viyola literatürüne kaynak ve bakış açısı sağlayacağı düşünüldügüñnden bu araştırmanın türünde çalışmaların tekrarlanması ve viyola ile ilgili yazılmış makalelerin incelenmesine yönelik çalışmaların da yapılması önerilmektedir. 


\section{EXTENDED ABSTRACT}

\section{Graduate Theses and Dissertations Written About The Viola in Turkey \\ Serkan Özay \\ Niğde Ömer Halisdemir University}

This research is directly related to previous research in terms of subject content and is a continuation of those studies. Articles related to graduate theses and dissertations studies on the Viola field are written by, Varış, 2012; Tebiş and Okay, 2013; Çeşit, 2015 and Sonsel, 2018. The aim of this research is to contribute to the later studies by determining the graduate theses and dissertations written about the Viola in Turkey and analyzing the distribution according to different variables. For this purpose, the questions to be answered are determined as follows:

- How are the distributions of graduate theses and dissertations written about the Viola in Turkey by type?

- How are the distributions of graduate theses and dissertations written about the Viola in Turkey by universities?

- How are the distributions of graduate theses and dissertations written about the Viola in Turkey by institutes?

- How are the distributions of graduate theses and dissertations written about the Viola in Turkey by the years they were written?

- How are the distributions of graduate theses and dissertations written about the Viola in Turkey according to their subjects?

The document analysis technique, which is one of the qualitative research methods, was used in the research. The documents of the research were searched in the search page of CoHE Thesis Center website with the search term of "viola" and by selecting the search category, the access type and the thesis type as "All". As a result of the search, 125 graduate theses were listed. In the advanced search option, 111 graduate theses and dissertations are listed after typing "viola" and "music" in search terms and selecting "all" in the search field. As a result of the detailed examination, the theses and dissertations directly related to the Viola, from 1990 to 2020, when the first research was 
made, were examined in terms of content and a total of 93 theses were determined with the access type of authorized/unauthorized. Finally, the crosscheck of the search was done by typing the titles and selecting "title" as the search field. A master's thesis with the term "viola" in its title but which has a subject of "biology" was excluded, so the number of theses and dissertations related to the field of the research was determined as 92 . A total of 81 theses, which constitute the sample of the research and are determined through purposeful sampling, which have authorized access and can be accessed in full text, have been analyzed. The research covers authorized studies that can be accessed from the database of CoHE Thesis Center until the first 8 months of 2020.

According to the data obtained from the thesis search page of CoHE Thesis Center, 92 theses and dissertations written between 1990 and 2020 related to the Viola in Turkey have been identified, but there are 11 studies that cannot be reached due to the permit status related to the subject of the research. Reviewing the permit status in dissertations written in all fields and opening it to the reach of researchers will contribute to the diversification of bibliography and content.

Viola-related graduate theses and dissertations of the article relating to the examination of recent data (57 dissertations: Sonsel, 2018) in the field of Viola written in the literature and 24 more graduate theses have been added to the literature, and the number of dissertations written at the doctoral level has increased threefold in two years. Although studies on the Viola are mostly master's theses, studies have increased significantly over the past four years, it may be recommended to increase the number of doctoral dissertation studies.

Gazi University and Mimar Sinan Fine Arts University were the universities where the most graduate thesis studies related to the Viola were performed. 83.33\% of doctoral dissertations were written at Gazi University, and the most proficiency in art thesis was written at Mimar Sinan Fine Arts University. In addition, during the period after the latest study, it was found that some universities increased their graduate thesis work on the Viola, while four more universities conducted graduate thesis work on this subject.

It was determined that 52 of the graduate thesis studies related to the Viola were carried out at the Institute of Social Sciences with a maximum rate of 
$64.20 \%$ and 5 of them were carried out at the Institute of Natural Sciences with a minimum rate of $6.17 \%$.

It was found that the most graduate thesis and dissertations studies related to Viola were conducted in 2019 with a rate of $12.34 \%$, the most doctoral theses related to the Viola were written in 2018 and 2019 with a rate of 33.34\% and the most Master's theses related to Viola were written in 2019 with a rate of $10.71 \%$. In 2017-2020, the number of graduate theses and dissertations written on the Viola was 21 with a rate of $25.92 \%$, meaning that the graduate theses and dissertations studies on the Viola were concentrated in the last four years.

It was observed that 23 of graduate theses and dissertations studies related to the Viola were about "education" with a rate of $28.39 \%$, and 20 of them were about "Work Analysis" with a rate of $23.46 \%$ in the second place. All doctoral dissertations were found to be about "Education" and proficiency in art thesis studies were found to be about "Work Analysis" with 9 theses and a rate of $47.37 \%$.

Since it is believed that it will provide a source and perspective for the Viola literature, it is recommended that studies be repeated in this type of research and that studies be conducted to examine articles written about the Viola.

\section{Kaynakça / References}

Akyürek, S. (2004). Müzik tarihinde viyolanın yeri veönemi. Yayımlanmamış yüksek lisans tezi. Çukurova Üniversitesi, Sosyal Bilimler Enstitüsü.

Alyörük, G. (2016). Türkiye' de gitar alanında yapılan lisansüstü tezler: Bir bibliyografya çalısması. Balkesir Üniversitesi Sosyal Bilimler Enstitüsü Dergisi, 19(35), 55-79. Doi:https://doi.org/10.31795/baunsobed.645333

Başdan, F. (2008). Keman eğitimi ve viyola eğitimi arastndaki benzerlikler ve farklliklarm karşılaştırmalı araştırması. Yayımlanmamış yüksek lisans tezi. Trakya Üniversitesi, Sosyal Bilimler Enstitüsü.

Baykal, Ç. (2012). Lisansüstü programlarda keman ve viyola eğitimi veren öğretim elemanlarınin çalğ pedagojisi ders içeriğine ilişkin görü̈sleri. Yayımlanmamış yüksek lsans tezi. Afyon Kocatepe Üniversitesi, Sosyal Bilimler Enstitüsü.

Benian, A.B. (2019). Viyola için bestelenmiş ve kemandan transkripsiyonu yaplmış başhca etüt kitaplarn üzerine bir inceleme. Yayımlanmamış yüksek lisans tezi. İstanbul Üniversitesi, Sosyal Bilimler Enstitüsü. 
Bilginer, M. (2001). Çalgı eğitiminde keman eğitimi ile viyola eğitiminin özdeşleştirilmesi. Yayımlanmamış yüksek lisans tezi. Marmara Üniversitesi Fen Bilimleri Enstitüsü.

Birel, A.S. veQader, H.M. (2017). Türkiye'de Kontrbas Konusunda Yazılmış Lisansüstü Tezler Üzerine Durum Tespiti. Yüzüncü Yıl Üniversitesi Eğitim Fakültesi Dergisi, 14(1), 1416-1439. Doi:http://dx.doi.org/10.23891/efdyyu.2017.50

Çeşit, C. (2015). Türkiye'de viyola üzerine yapılan lisanüstü tezlerin incelenmesi. The Journal of Academic Social Science Studies, 38, 445-462. Doi:http://dx.doi.org/10.9761/JASSS3035

Delikara, A. (2019). Türkiye'de müzik teknolojileri alanında yazılmış lisanüstü tezler. Ekev Akademi Dergisi, 23 (79), 1-16. Doi:http://dx.doi.org/10.17753/Ekev1108

Demirbatır, R.E. (2001). Yaylı çalgılar yüksek lisans, doktora ve sanatta yeterlik tez bibliyografyası. Uludă̆ Üniversitesi Eğitim Fakültesi Dergisi 19(1). 143-150. https://dergipark.org.tr/tr/pub/uefad/issue/16676/173254 adresinden erişilmiştir.

Kaptanoğlu E. ve Çanakçı. P. (2015). Türkiye'de vokal müzikte piyano eşlik alanında yapılmış yüksek lisans, doktora ve sanatta yeterlik tezleri. Elektronik Sosyal Bilimler Dergisi, 14(55), 198-206. Doi:https://doi.org/10.17755/esosder.20305

Kumtepe, D.G. (2019). Keman çalan öğrencilerin viyola çalabilme durumları ve bu durumun viyola eŏitiminde kullanılabilirliği. Yayımlanmamış doktora tezi. Gazi Üniversitesi, Eğitim Bilimleri Enstitüsü.

Ligeti, G. (2001). Sonata for solo viola. 08.08.2020 tarihinde https://edisciplinas.usp.br/pluginfile.php/3037282/mod folder/content/0/Gyorgy $\% 20 \mathrm{Li}-$ geti\%20-\%20Sonata\%20for\%20viola\%20solo.pdf?forcedownload=1 adresinden erişilmiştir.

Okay, H. ve Kurtaslan, Z. (2013). Keman ve viyolada ton üretimi. JRET - Ĕğitim ve Öğretim Araştırma Dergisi. 2(1), 274-283. http://www.jret.org/FileUpload/ks281142/File/29a. hakan_okay.pdf adresinden erişilmiştir.

Orhan, Ş.Y. (2011). Türkiye'de viyolonsel alanında yapılmış yüksek lisans, doktora ve sanatta yeterlik tezleri. Kastamonu Eğitim Dergisi 20(2) 701-716. https://dergipark.org.tr/tr/pub/kefdergi/issue/48697/619557 adresinden erişilmiştir.

Orhan, Ş.Y. ve Tunca, B.E. (2014). Türkiye'de oda müziği alanında yapılmış yüksek lisans, doktora ve sanatta yeterlik tezleri. Folklor/edebiyat, 20 (80) 207-219. https://dergipark.org.tr/tr/pub/fe/issue/26057/274479 adresinden erişilmiştir.

Özay, S. (2017). Türkiye'de kabak kemane üzerine yapılmış tezlerin incelenmesi. 4. Türk Dünyası Araştırmalan Sempozyumu Bildiriler Kitabı, 647-652.

Özkarar, G. (2017). Tarihsel süreçte gelişen viyola ekolleri. İstanbul:Hiperlink yayınları. 
Öztürk, F. veÖzay, S. (2008). Keman ve viyola eğitiminde kullanılan Mazas special etudes Op.36metodunun sağ ve sol el teknikleri yönünden incelenmesi. Gazi Üniversitesi Gazi Eğitim Fakültesi Dergisi, 28 (3). http://www.gefad.gazi.edu.tr/tr/pub/issue/6746/90702 adresinden erişilmiştir.

Puy, G. (2020). Bilimsel araştırma nedir? https://www.iienstitu.com/blog/bilimsel-arastirma-nedir adresinden 13.05.2020 tarihinde erişilmiştir.

Sonsel, Ö.B. (2018). Türkiye' de viyola alanında yazılmış lisansüstü tezlerin incelenmesi. Mehmet Akif Ersoy Üniversitesi, Eğitim Fakültesi Dergisi, 47. 340-359. Doi: https://doi.org/10.21764/maeuefd.403244

Şekerkaran, K. (1997). Viola. Filarmoni Sanat, 144, 31-33.

Tebiş, C. ve Okay, H. H. (2013). Türkiye' de müzik sanatı ve eğitiminde keman ve viyola konulu lisansüstü tezlerin konu ve yöntem olarak incelenmesi. International Journal of New Trends in Arts, Sports E Science Education. 2(2), 11-20.

Toptaş, B. (2013). Türkiye' de piyano üzerine yapılmış lisansüstü çalışmalar. International Journal of Social Science Studies, 6(3), 715-728. Doi:http://dx.doi.org/10.9761/JASSS710

Varış, Y.A. (2002). Viyola ve kemanın benzer ve farklı özelliklerinin fiziki ve teknik kullanmm açısından incelenmesi ve bu özelliklerin ortaya çıkardiğı ilişkilerin viyola eğitimine yansıması. Yüksek lisans tezi. Abant İzzet Baysal Üniversitesi Sosyal Bilimler Enstitüsü.

Varış, Y.A. (2012). Türkiye'de viyola üzerine yazılmış lisansüstü tezlerin analizi. The Journal of Academic Social Science Studies, 5(8), 1247-1260. Doi:http://dx.doi.org/10.9761/jasss_484

Yıldırım, A. ve Şimşek, H. (2018). Sosyal bilimlerde nitel araştırma yöntemleri. Ankara: Seçkin Yayınevi.

Yılmaz, C. (2017). Viyolanın 9.yüzyıldan günümüze gelişimi ve Andrea AMATI'nin viyola formuna getirdiği yenilikler. Yüksek Lisans Tezi. Mersin Üniversitesi, Güzel Sanatlar Enstitüsü.

\section{Kaynakça Bilgisi / Citation Information}

Özay, S. (2020). Türkiye'de Viyola alanında yazılmış lisansüstü tezler. OPUS-Uluslararası Toplum Araştırmaları Dergisi, 16(Eğitim ve Toplum Özel Sayıs1), 6344-6361. DOI: 10.26466/opus.784467 